\title{
The Efficiency of in-situ Cleaning Methods for Minimizing Electron Beam Induced Contamination
}

\author{
Hamed Parvaneh, Hendrix Demers, and Eric Lifshin
}

College of Nanoscale Science and Engineering, University at Albany - SUNY, 255 Fuller Road, Albany, New York 12203

As the features of interest in state-of-the-art integrated circuits (ICs) are getting smaller the ability of scanning electron microscopes (SEMs) to see things in detail in semiconductor metrology is worsening. One important reason is the formation of an electron beam induced contamination layer that seriously deteriorates image contrast and resolution. It can even be found in SEMs with so-called clean vacuum systems (no oil pumps). Different sources of the environmental contamination, including the sample itself have been discussed elsewhere [1]. This contamination layer is commonly attributed to the polymerization of low molecular weight hydrocarbon $(\mathrm{HC})$ molecules on the surface of the sample following interaction with the electron beam. One way of removing them from the system is to promote their removal by oxidation processes [2].

In the current study we have evaluated the efficacy of this approach based on the use of an Evactron ${ }^{\circledR}$ de-contaminator (XEI, Evactron ${ }^{\circledR} 25$ D-C) installed on a Dual beam FIB/SEM chamber (FEI, Nova NanoLab 600) equipped with an Energy Dispersive X-ray Spectrometer (Princeton Gamma-Tech, $\mathrm{Si}(\mathrm{Li})$ ). The dual beam FIB/SEM was selected because of its usefulness in examining the grain structure of sub-100nm copper interconnects. One drawback in observing grain structure is the flatness of the finished surfaces prepared by FIB, which significantly reduces the variation in the secondary electron (SE) yield associated with any topography on the surface. Unlike the transmission electron microscopes where the diffraction contrast is usually the dominant mechanism for grain contrast, in SEMs the contrast is a result of point to point variation in the SE yield. This can be due to surface topography, chemical composition or crystallographic effects. Since in the case of FIB-prepared copper interconnects, the surface is flat and there is no chemical variation from grain to grain, the contrast will depend primarily on variations in crystallographic effects which are generally small compared to the other two and thus maybe difficult to observe.

While our ultimate goal is to improve contrast in cross sectional images of microelectronic interconnects, our initial experiments involve measuring contamination rate buildup on a bare silicon substrate. The carbon buildup in a square raster $2.5 \mu \mathrm{m}$ on a side was measured as a function of time both before and after the use of the Evactron ${ }^{\circledR}$ de-contaminator. To avoid the possible effect of different currents in the before and after data, a graphite standard sample was used and the ratio of carbon peak intensity from HC layer to graphite standard is presented (k-ratio). The results shown in Figure 1, clearly indicates that there is little to no carbon buildup after using the de-contaminator. As an additional observation, the carbon intensity on the square produced in the first experiment, was remeasured after cleaning with Evactron ${ }^{\circledR}$. Since almost the same k-ratio was obtained, it is assumed that no polymerized carbon was removed by the Evactron ${ }^{\circledR}$ for the conditions used in this experiment. Figure 2 also shows the oxygen and silicon signals as a function of time both before and after the cleaning. Since it was verified that there was no variation in probe current before and after cleaning, 
raw data is presented for silicon and oxygen as a function of time. There appears to be no significant difference in the oxygen signal before and after cleaning, suggesting that most of the oxygen has been removed by the vacuum pumps. The attenuation of the silicon signal in the before-cleaning data is to be expected as the buildup of carbon contamination layer obscures the silicon substrate. Work is in progress to examine the effect of various substrates including FIB cross sections of copper (which are very prone to oxidation) to more fully characterize the nature of the hydrocarbon contamination layer buildup process.

\section{References}

[1] R. Vane et al. Microsc Microanal. 11 (Suppl 2) (2005) 900.

[2] R. Vane. Microsc Microanal. 12 (Suppl 2) (2006) 1662.

[3] This research is supported by the Semiconductor Research Corporation's Global Research Collaboration under the New York Center for Advanced Interconnect Science \& Technology (NYCAIST) Task 1292.039

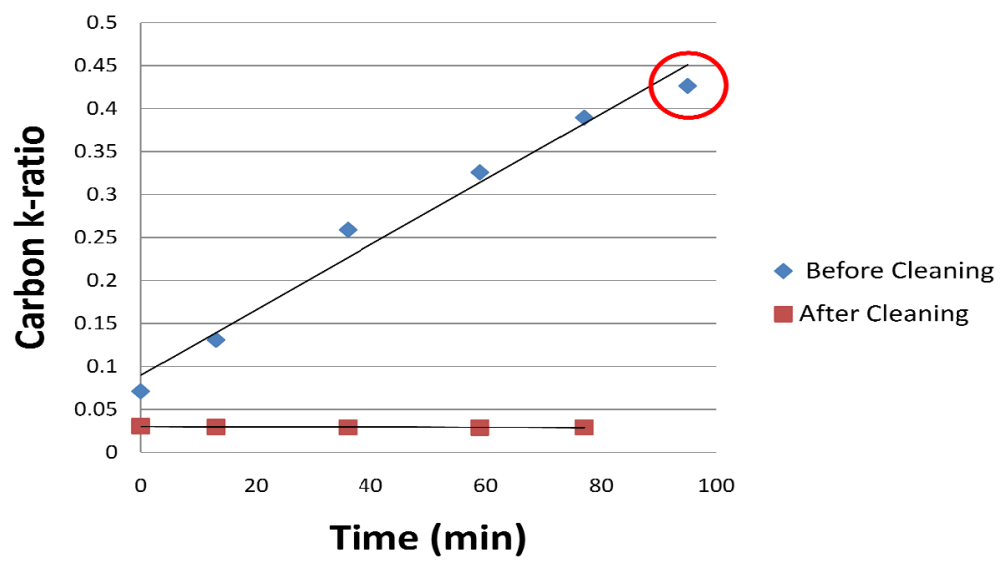

FIG. 1. Carbon k-ratio as a function of time before and after cleaning the chamber with Evactron ${ }^{\circledR}$ decontaminator. The data point highlighted in red circle represents the measurement performed on the very same contamination square produced in the first experiment right after cleaning the chamber. Experiments were performed on a square of $2.5 \mu \mathrm{m}$ with a probe current of $0.84 \mathrm{nA}$ and accelerating voltage of $2 \mathrm{kV}$.

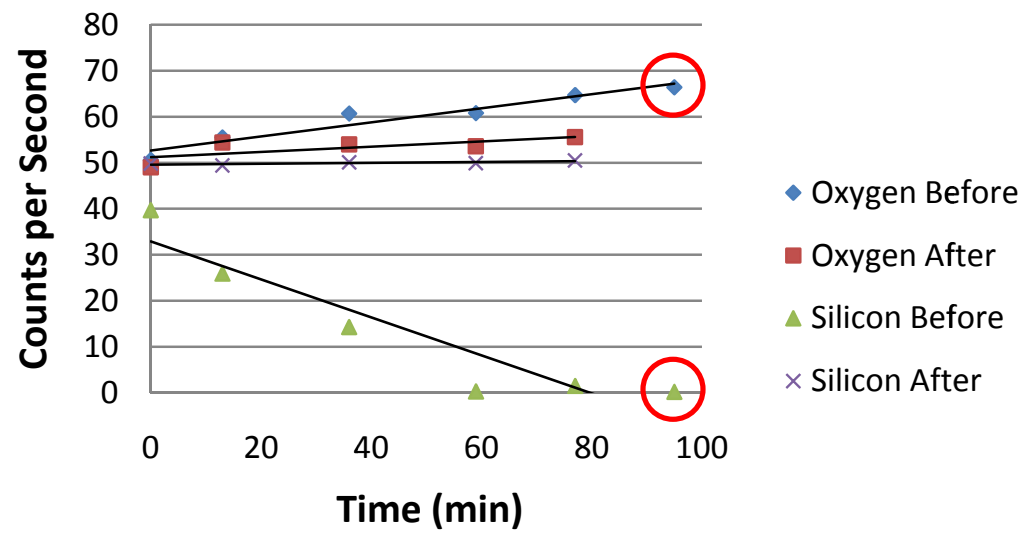

FIG. 2. Oxygen and Silicon signals as a function of time before and after cleaning the chamber with Evactron ${ }^{\circledR}$ de-contaminator. The data point highlighted in red circle represents the measurement performed on the very same contamination square produced in the first experiment right after cleaning the chamber. 